\title{
Francisco Zúñiga Urbina* \\ Nueva Constitución para Chile. Las "bases" y las nuevas ideas político-constitucionales
}

\section{Palabras preliminares}

A brir fuego en el debate constitucional-constituyente exponiendo las "bases" de una nueva Constitución para Chile y las nuevas ideas político-constitucionales, presenta como desafío plantear las ideas fuerza de un discurso constitucional de centro-izquierda fraguado durante largo tiempo, desde la remota crítica formulada en 1980 por el Grupo de Estudios Constitucionales a la Constitución de 1980 y el gran fraude que la vio nacer, y que al mismo tiempo en cuanto discurso constitucional debe ser contemporáneo e ideológicamente abierto a las ideas modernas, conectando todo ello con nuestra realidad histórico-política. ${ }^{1}$ En este sentido no hay modelos ni transiciones ni de arreglos institucionales a copiar.

No pretendo en esta exposición recoger una relación ad litteram del Programa de Gobierno de la coalición Nueva Mayoría que encabeza la doctora Michelle Bachelet Jeria y actual presidenta electa; sino plantear ideas fuerza que han estado presente en el debate del Programa, en el que han participado un buen número de egresados y docentes de la Facultad de Derecho de la Universidad de Chile. Luego, abordo la exposición con la libertad de pensar que la academia exige, y por ello sin comprometer en nada al nuevo gobierno en formación. En este mismo orden de ideas, la exposición se hará cargo de algunas ideas fuerza que no están en el Programa pero sí están en el debate constitucional-constituyente.

El debate constitucional-constituyente se produce hoy en un nuevo ciclo político posttransición, en la cual un hito relevante fue la reforma constitucional de 2005 a veces incomprendida en su contenido progresivo ciertamente, su trabajoso alumbramiento y su complejo contexto. ${ }^{2}$

Profesor titular de Derecho Constitucional, Universidad de Chile.
1 ZÚNIGga Urbina, FranCISCO, "Nueva Constitución del Bicentenario y Operación Constituyente”, en libro colectivo En nombre del pueblo. Debate sobre el cambio constitucional en Chile, ICSO-UDP-Heinrich Böll S., Santiago, 2010, pp. 278-286.

2 Consultar libro colectivo Reforma Constitucional, coordinador Francisco Zúñiga Urbina, Editorial LexisNexis, Abeledo Perrot, Santiago, 2005. 
En este nuevo ciclo ya no tiene cabida el falso consenso constitucional que marcó indeleblemente el ciclo reformador de la transición, de 1989 a 2005, es decir no es de recibo que una minoría pretenda bloquear una reforma total a la Constitución y/o vetar sus contenidos; asilada en la hiper-rigidez de la Carta impuesta. La Constitución defensiva, seguro o parapeto de los herederos ideológicos del régimen autoritario, ya no se soporta a sí misma, y es innegable una creciente deslegitimación de las instituciones (crisis de representatividad).

Por lo demás un deseable "patriotismo constitucional" o nueva "religión civil" que cohesione a la comunidad política en base a valores y definiciones institucionales mínimas compartidas; sólo puede ser obtenida a partir de un procedimiento genético de la nueva Constitución que ha sido adjetivado correctamente a través de los atributos siguientes: institucional, democrático y participativo. ${ }^{3}$

En consecuencia, la nueva Constitución se piensa, delibera, comunica, acuerda y escribe en una "hoja en blanco", no desde cero, pues Chile ha cumplido su bicentenario y posee una rica tradición institucional republicana que debemos rescatar, una "hoja en blanco" viene a significar un proceso constituyente en vía de reforma total de la Constitución según las previsiones del Capítulo XV de la Constitución, sin bloqueos decisionales y vetos de contenidos iusfundamentales de minorías que piensan y actúan en razón de un cálculo mezquino que se resume en mantener posiciones de poder y orden político-ideológico en el Estado; y que es una herencia del pasado autoritario.

De esta manera, en diálogo con la ciudadanía, superaremos los enclaves institucionales heredados de la dictadura o trampas institucionales, que hacen a no dudarlo de la vieja Constitución una "Constitución tramposa" y se abrirá el horizonte ideológico de la Constitución y de la República a las ideologías y tradiciones constitucionales liberal, democrática y social ${ }^{4}$.

\section{La Constitución de los Derechos}

\section{Presentación. Chile debe dejar de ser un país insular}

A cuarenta años del golpe de Estado (o si quiere en propiedad revolución de 1973) se cierra un ciclo (dictadura y transición) y se abre otro ciclo histórico-político en nuestro país. En 1973 se interrumpe una larga continuidad de instituciones republicanas; instaurándose un orden constitucional otorgado, autoritario y neoliberal; y con motivo de tal golpe se produce una fractura en el alma nacional y un tremendo trauma colectivo, que más allá de las tareas de reconciliación, verdad y justicia que se han emprendido. El presente y por-venir caracterizado como un nuevo ciclo,

3 Habermas, JÜrgen, Más allá del Estado Nacional, Editorial Trotta, Madrid, 2001.

4 Atria Lemaitre, Fernando, La Constitución Tramposa, LOM, Santiago, 2013. 
exige pensar en una nueva Constitución, uno de cuyos centros de gravedad sean los derechos humanos; los que fueron violados sistemáticamente, como una política de Estado, por la dictadura y sus aparatos represivos y que, todavía hoy, sectores de la población, pretenden negar o justificar.

Una nueva Constitución de derechos debe recoger los derechos civiles y políticos clásicos que tienen como titular por antonomasia a los individuos; pero además, debe recoger nuevos derechos civiles que ponen el acento en la autonomía física, intelectual y moral de las personas; nuevos derechos políticos que ponen el acento en la autonomía e igualdad política de las personas; $y$, nuevos derechos económicos, sociales, culturales y ambientales que ponen el acento en la igualdad social y en la inserción de los individuos y sus grupos en el medio ambiente y la naturaleza.

Estos nuevos derechos y la nueva Constitución de los derechos encuentran en el derecho internacional general y en el derecho internacional convencional, una importante fuente de garantía complementaria que el Estado de Chile no puede desatender.

Por ende, se requiere de una definición toral en la Constitución a favor de los derechos humanos y de una cultura de los derechos humanos en que la fuente constitucional y legal sea también complementada por tratados internacionales, ratificados y vigentes, de suerte que la plena obligatoriedad de estos tratados para el Estado y sus órganos vaya acompañada del compromiso en orden a no adoptar ninguna decisión o acto estatal que niegue la obligatoriedad de tales derechos, los impida o dificulte, de suerte que la mentada obligatoriedad vaya acompañada del cumplimiento de buena fe de estos instrumentos. En consecuencia, el deber de los órganos del Estado respetar, promover y asegurar, en todos sus niveles de protección, el pleno ejercicio de los derechos humanos, propendiendo a su progresividad, expansividad y óptima realización posible.

En la actualidad, después de dos guerras mundiales, guerras civiles, conflictos armados, golpes de fuerza y guerras de liberación nacional del siglo XX, los derechos humanos son parte de la cultura de occidente y de un mundo globalizado. Son también, los derechos humanos, de algún modo, el mínimo ético universal en que los pueblos civilizados acuerdan sus formas de convivencia; Chile no puede ser un país insular en materia de derechos humanos, debe abrirse internacionalmente a ellos y debe tener un rol activo en su desarrollo. 5

\section{Más y nuevos derechos}

La nueva Constitución, fruto de la confluencia de las tradiciones liberal, democrática y social requiere de un completo y equilibrado catálogo de derechos, deberes y garantías.

5 Bobbio, Norberto, El futuro de la democracia, FCE, México DF, 2001. 
En consecuencia, se propone garantizar un catálogo abierto y progresivo de derechos que incluye: el derecho a la igualdad y a la no discriminación, el derecho a la vida, integridad física y psíquica, el derecho a la libertad de conciencia, el derecho a la libertad de expresión (derecho a la información, libertad de opinión e información y pluralismo informativo), los derechos de los niños, niñas y adolescentes, el derecho a la intimidad y derechos sexuales y reproductivos, el derecho de propiedad, el derecho al debido proceso, el derecho al medio ambiente, los derechos políticos, el derecho a la participación, el derecho a la protección de la salud, derechos de los consumidores y usuarios, el derecho a la seguridad social, los derechos de las personas con discapacidad y de la tercera edad, el derecho a la educación, el derecho al trabajo, el derecho de huelga, el derecho a la negociación colectiva, el derecho a la vivienda, el derecho a la cultura, y los derechos colectivos.

De esta manera, frente a los derechos más tradicionales, se hace necesario incorporar derechos individuales y colectivos que den cuenta de la relación del individuo con el Estado y la sociedad civil organizada y plural. En consecuencia, debe haber una completa disposición constitucional habilitante para que el Estado y la ley puedan brindar satisfacción efectiva a los derechos, de forma universal, igualitaria y sin segregación, superando el déficit estructural que la vieja Constitución tiene en materia de derechos de la personalidad, políticos, y derechos económicos, sociales y culturales. Se reconoce el derecho igualitario al matrimonio y a fundar una familia. Le corresponde al Estado favorecer el igual acceso de mujeres y hombres a cargos de elección popular, así como a puestos de responsabilidad profesional y social. Para ello, la nueva Constitución debiera instar medidas de acción positiva que permitan alcanzar la mayor igualdad posible efectiva, incluyendo las leyes cuotas y considerando los estándares de temporalidad, proporcionalidad y afectación.

La Constitución debe garantizar que ninguna mujer sea puesta en peligro por causa de su embarazo o parto así como que ninguna mujer sea objeto de prácticas como el embarazo forzado, la esterilización o el aborto forzado. Está en el debate de hoy recoger en la Constitución un mandato de habilitación, de suerte que la ley garantice y regule la interrupción voluntaria del embarazo; sin perjuicio de que el programa plantee dos hipótesis de interrupción.

El Estado debe favorecer el acceso y participación en condiciones igualitarias entre mujeres y hombres a cargos de elección popular. Se debe garantizar el ejercicio efectivo de los derechos políticos de las mujeres prestando especial atención al derecho a ser elegidas y a ocupar cargos de elección popular, nominación en las instancias de dirección y decisión de los poderes públicos, y en los partidos políticos, y representación de países en instancias internacionales, introduciendo criterios de paridad en la representación de ambos sexos. Para ello se deben implementar medidas de acción positiva que permitan alcanzar la paridad en los cargos de representación popular. 
Los derechos fundamentales contenidos en tratados internacionales ratificados y vigentes por Chile se entenderán parte del ordenamiento jurídico y tendrán aplicación preferente frente a otras fuentes formales de derecho interno cuando resulten más progresivas y optimizadoras en el aseguramiento de derechos. La Constitución deberá prever una regla de incorporación de tratados internacionales al derecho interno y también una regla de habilitación que, con las formas exigidas, permita la delegación de competencias soberanas del Estado en organismos internacionales o supranacionales.

Los derechos fundamentales deben ser interpretados armónicamente con el acervo jurisprudencial emanado de los órganos internacionales y supranacionales de protección de derechos humanos. La ley debe regular cómo el Estado dará cumplimiento a las sentencias de los tribunales internacionales de derechos humanos. Esta legislación debe indicar claramente cómo los tres poderes del Estado deben intervenir y cumplir de buena fe las sentencias internacionales. Chile desde su nueva Constitución debe estar abierto al mundo, no sólo en su economía sino en su organización política, en la mantención de la paz, en la cooperación, en la integración latinoamericana, y ciertamente, en su cultura en general y en la cultura de los derechos humanos.

\section{Garantías}

La nueva Constitución debiera desarrollar los estados de excepción constitucional con las limitaciones generales a los derechos, definiendo estrictamente los supuestos de hecho que permitan limitarlos; con estricta sujeción a estándares internacionales, tales como los principios de Siracusa; los que deberán quedar plasmados en su legislación.

Se debe garantizar una ampliada reserva de ley en materia de derechos fundamentales; poniendo fin a reservas reglamentarias, como las existentes hoy en materia de derecho de reunión y de libertad de cultos.

Todos los derechos deben poseer -según la doctrina y jurisprudencia dominante- la misma relevancia para el desarrollo pleno de las personas y, además, se deben asegurar formas de control judicial sobre los derechos económicos, sociales y culturales que permiten vincular a las autoridades administrativas; sin menoscabar las políticas públicas progresivas y fiscalmente responsables en procura de derechos prestacionales. Sin sustituir el criterio del Gobierno y la Administración en materia de diseño y ejecución de las políticas públicas, se propone que la Carta Fundamental garantice un amplio proceso de amparo ordinario de derechos civiles, políticos como sociales, económicos y culturales, y dejar a la ley, la regulación del modo en que cada derecho habrá de ser cautelado y la determinación de la competencia de los tribunales que confieran tutela constitucional a estos derechos.

Finalmente, en materia de garantías, la nueva Constitución prevé la creación de un Defensor del Ciudadano o Defensor del Pueblo, concebida como una autori- 
dad sin imperio o persuasiva encargada de velar por los derechos de las personas y administrados frente a la Administración y los servicios de interés público. Esta autoridad podrá formular recomendaciones, procesar quejas de los ciudadanos, instar a la efectivización de responsabilidades, instar a la activación de controles judiciales de amparo ante los tribunales del Poder Judicial y de constitucionalidad ante el Tribunal Constitucional, y favorecer ante los demás órganos del Estado a la defensa y promoción de los derechos de las personas. Sobre esta importante magistratura volveré más adelante.

\section{Deberes constitucionales}

En materia de deberes constitucionales, la nueva Constitución debe hacerse eco de la hoy clásica fórmula de la Declaración Universal de los Derechos Humanos de 1948, que sitúa a las personas y sus grupos no sólo frente al Estado, sino frente a la comunidad en que viven, de suerte que los deberes superen concepciones individualistas que niegan la necesidad de la cooperación y la solidaridad social. En consecuencia, la Constitución deberá establecer deberes relativos a la vida pacífica, el respeto de los derechos, la contribución a una sociedad solidaria, el cumplimiento con las cargas reales y personales que establezca la ley; los deberes para con el Estado nacional, sus valores e intereses permanentes y los deberes relativos al respeto y cumplimiento de la Constitución y la ley.

\section{La Constitución y sus decisiones fundamentales: la República, el Estado Social y el Estado Regional.}

\section{Fundamentos del Estado, la sociedad y la economía}

Chile debe superar el déficit de legitimidad de la Constitución vigente. Ésta Constitución (o decreto ley fundamental) se caracteriza por ser "otorgada" unilateralmente, autoritaria en lo político y neoliberal en lo económico. La nueva Constitución debe inspirarse en la tradición democrática y republicana chilena, en la que confluyan las tradiciones constitucionales liberal, democrática y social y que sea fruto de un auténtico consenso constitucional. Para ello debe superar los déficits democráticos del arreglo institucional y del ejercicio del poder constituyente derivado. ${ }^{6}$

La nueva Constitución debe cimentarse sobre las siguientes normas de principio reflejo de decisiones fundamentales: i) Estado social y democrático de Derecho; ii) Chile como república democrática; iii) La representación y la participación; iii) Fortalecimiento de la descentralización; iv) Reconocimiento y fortalecimiento de derechos fundamentales, en especial los derechos de igualdad de las mujeres, los derechos políticos y los derechos sociales; v) Un Estado laico que respeta el 
pluralismo; vi) Reconocimiento de los pueblos indígenas; vii) Sistema político que represente la voluntad de los chilenos y chilenas; viii) Institucionalidad que proteja y esté al servicio de la dignidad de las chilenas y chilenos, respetando y representando su voluntad soberana. ${ }^{7}$

i) El Estado social y democrático de derecho. Comprende no sólo la distribución del poder político sino que también un conjunto de deberes de "buen gobierno" y de satisfacción de necesidades públicas que son consustanciales a la legitimidad misma del Estado y del poder. En su centro está la satisfacción de las necesidades básicas de las personas aseguradoras de un mínimo de igualdad, como el trabajo y las remuneraciones, la salud, la previsión social, la educación, la vivienda, entre otros. El Estado social o "sociedad de garantías” es el presupuesto de una ciudadanía social.

ii) La república democrática. Ésta se fundamenta en el equilibrio entre representación política y la participación. Considera fundamental la elección de los cargos públicos, la alternancia en el poder y la responsabilidad en el ejercicio del poder. Esencial es la limitación de la reelección indefinida de los cargos públicos de elección popular de manera de asegurar una permanente renovación de las élites políticas.

iii) Fortalecimiento de la descentralización y Estado regional. La nueva Constitución profundizará en las posibilidades de descentralización, desconcentración, delegación y coordinación del poder central en estructuras periféricas y en materias políticas y administrativas, de manera de hacer más representativo el poder del Estado en todo el territorio nacional, acercando a los ciudadanos a sus autoridades y a la toma de decisiones, contribuyendo a una mayor legitimidad y empoderamiento.

iv) Igualdad entre mujeres y hombres. El reconocimiento de los derechos de igualdad entre los sexos exige a la nueva Constitución el establecimiento de condiciones específicas que permitan superar las barreras que han mantenido a las mujeres lejos de los espacios de poder. Se considera el establecimiento de leyes de cuotas electorales, el apoyo y promoción de los mecanismos concretos dirigidos a la igualdad de deberes en el ámbito doméstico y en el cuidado de los niños, mecanismos de garantía de competencia legítima para cargos de responsabilidad profesional y social (que incorpore una igualdad real de oportunidades).

e. Estado laico que respeta el pluralismo. La nueva Constitución establecerá, explícitamente, por primera vez en nuestra historia republicana, la laicidad del Estado, en un marco de pleno respeto por las creencias religiosas y éticas de las personas, y la práctica del culto.

7 Böckenförde, ERnSt Wolfgang, Estudios sobre el Estado de Derecho y la democracia, Trotta, Madrid, 2000. 
f. Asimismo, se hace necesario superar el derecho constitucional del enemigo garantizándose efectivamente el más pleno pluralismo político e ideológico, y la descriminalización del disidente; que adoptan las presentaciones de una seudo "democracia militante" o penalización de "conductas terroristas"; como si la legislación penal no fuere suficiente para conservar la paz social.

g. Reconocimiento de los pueblos indígenas. La nueva Constitución debe establecer el reconocimiento iusfundamental del los pueblos indígenas, sus tradiciones, lenguas, costumbres, aporte a la cultura y derechos colectivos que se harán efectivos a través de mecanismos de consulta y participación.

\section{Derechos fundamentales y sus garantías}

La nueva Constitución, fruto de la confluencia de las tradiciones ideológicas y constitucionales liberal, democrática y social requiere de un catálogo de derechos, deberes y garantías constitucionales moderno, completo, equilibrado y garantizado en diversos niveles de protección ${ }^{8}$.

Como decíamos a propósito de "más y nuevos derechos", se propone en las "bases" garantizar un catálogo abierto y progresivo de derechos que incluye: el derecho a la igualdad y a la no discriminación, el derecho a la vida, integridad física y psíquica, el derecho a la libertad de conciencia, el derecho a la libertad de expresión, los derechos de los niños, niñas y adolescentes, el derecho a la intimidad y derechos sexuales y reproductivos, el derecho al debido proceso, el derecho al medio ambiente, los derechos políticos, el derecho a la participación, el derecho a la protección de la salud, el derecho a la seguridad social, los derechos de las personas con discapacidad y de la tercera edad, el derecho a la educación, el derecho al trabajo, el derecho de huelga, protección de las remuneraciones y un derecho de negociación colectiva por rama de actividad, el derecho a la previsión social, el derecho a la vivienda, el derecho a la cultura, y los derechos colectivos.

Asimismo, se establecerá un mandato para que el Estado y la ley puedan brindar satisfacción efectiva a los derechos, de forma universal, igualitaria y sin segregación, superando el déficit estructural que la vieja Constitución tiene en materia de derechos, en especial de derechos económicos, sociales y culturales. En materia de derecho de propiedad se fortalecerá en función social y las obligaciones que la riqueza genera. En este mismo orden de ideas, se deberá incorporar una cláusula constitucional de dominio público de las aguas equivalente al dominio de las minas. Finalmente, la nueva Constitución debe disponer que la ley fijará regalías para la explotación y comercialización de recursos naturales que sean de dominio de la nación. 
En materia de deberes constitucionales, como decíamos, se propone que éstos incorporen la idea de la cooperación y la solidaridad social. En especial es necesario reformular los derechos de propiedad y libre iniciativa económica de manera de proteger y equilibrar la iniciativa privada en la economía con la función social que estos derechos tienen, en especial el deber de colaboración con los intereses sociales.

Por último, en materia de garantías se propone que el proceso de amparo constitucional ordinario ante los tribunales del Poder Judicial se extienda a todos los derechos fundamentales: civiles, políticos, económicos, sociales y culturales, a través de las acciones, procedimientos y los tribunales que establezca la ley, la deberá establecer el tipo de tutela brindada a través del amparo; todo sin menoscabo de las decisiones del Gobierno, de la Administración y del Legislador en la cobertura progresiva de los derechos sociales.

\section{Régimen politico: del Presidencialismo al Presidencialismo Flexibilizado o el Semi-Presidencialismo}

Chile debe superar la tendencia autoritaria que ha tenido nuestro régimen de gobierno desde el siglo XIX y avanzar a un sistema en el cual el poder del Presidente de la República se equilibre con el del Congreso Nacional, de acuerdo con el respeto por los principios de democracia, representación y participación. Pero tal equilibrio debe ir de la mano de un fortalecimiento de la gobernabilidad y de las coaliciones estables.

En este campo, se han formulado en el debate constitucional dos opciones, no recogidas en el Programa, que buscan fortalecer la gobernabilidad, facilitando mecanismos de colaboración del Parlamento con el Gobierno. Por una parte, la primera opción es la instauración de un régimen presidencial flexible o moderado, en el cual se establecen límites al poder del Presidente de la República por medio de fortalecer las atribuciones del Congreso Nacional en materias tales como el control presupuestario; que los Ministros puedan ser parlamentarios y, por ende, sujetos al constante escrutinio del Congreso y que respondan políticamente ante éste; iv) ampliar el plazo de duración del mandato presidencial a 5 o 6 años, o bien 4 años con posibilidad de una reelección inmediata. Esta alternativa supone hacer modificaciones profundas al actual sistema, pero no implica su sustitución.

La otra opción supone la sustitución completa del régimen político, pasando a un régimen semi-presidencial, cuya principal manifestación es la separación entre la figura del Jefe de Estado -encargado de la representación internacional del país y es el jefe de las fuerzas armadas- y el Jefe de Gobierno, a cargo de la conducción política y administrativa del país. En este sistema, el Congreso Nacional y su cámara baja tienen un papel central puesto que participa en la elección del Jefe de Gobierno y de los Ministros de Estado, los que quedan sometidos a mecanismos de confianza, control, responsabilidad política y constitucional. 


\section{Congreso Nacional}

En el marco de la reforma al régimen político, con independencia del modelo presidencial flexible moderado o semi-presidencial, se propone diferenciar los roles institucionales de las cámaras del Congreso Nacional, guardando coherencia esta diferenciación con el régimen político y la nueva forma jurídica de Estado regional que el fortalecimiento de la descentralización considera.

En consecuencia, se puede considerar la idea de que el Senado sea la cámara de representación territorial de las regiones, conservando, en todo caso, sus atribuciones moderadoras, cuasi judiciales y políticas. Se busca, por otro lado, fortalecer y ampliar sus atribuciones de confirmación en el nombramiento de altos cargos de Gobierno y Administración y en la integración de otros órganos supremos del Estado. La elección de los senadores será por cuatro años o por el período que dure el mandato presidencial, siendo posible reelección por una sola vez.

La Cámara de Diputados mantendrá su rol político por excelencia, y sin perjuicio de que ambas cámaras mantienen su rol en la formación de la ley, en caso de discrepancia primará la decisión de la Cámara de Diputados.

\section{Supresión de quórums especiales para la aprobación de la ley y potestad reglamentaria para una gestión eficiente del Ejecutivo}

La nueva Constitución, basada en los principios de democracia, participación y representación, reconoce el valor de la ley como expresión de la mayoría política como un valor esencial y de la consiguiente deliberación, por lo mismo se plantea la existencia de un quórum común o general de mayoría de parlamentarios presentes en ambas cámaras para la aprobación de las materias que requieran ley, y eliminar, como regla general, las leyes de supermayorías, los quórums elevados o reforzados para la modificación de las leyes, reservando excepcionalmente los quórums especiales para materias que dicen relación con reforma de la Constitución, insistencias, veto presidencial, entre otras que se establezcan.

Asimismo, la potestad reglamentaria del Gobierno debe tener la flexibilidad necesaria para la ejecución de las políticas públicas y para la debida ejecución de la ley, de manera de atender las necesidades de los chilenos y chilenas de manera eficaz y oportuna, eliminando barreras burocráticas que muchas veces los perjudican.

Una idea central es retornar a un sistema de reparto de potestades normativas GobiernoCongreso Nacional en que prime como norma de clausura la ley.

\section{Administración militar y policial, Administración institucional, control de la Administración del Estado y Justicia de Cuentas}

Se abre camino en el debate constitucional un conjunto de ideas político-constitucionales sobre régimen político, Gobierno y Administración, algunas recogidas en el 
Programa de Bachelet y otras no, pero que son dignas de consideración. En materia de régimen político se abre un debate en el marco de un esquema semi-presidencial o presidencial flexible, un esquema dualista en que el Presidente de la República y el Gobierno son la cabeza de la Administración del Estado y en que los Ministros son las autoridades sectoriales de la ejecución de políticas públicas y en tal medida son responsables política y constitucionalmente.

Asimismo, se postula enriquecer el derecho público reconociendo constitucionalmente ciertos principios que ordenan la Administración del Estado, tales como la legalidad, eficiencia, eficacia, probidad, transparencia, servicio del interés general, entre otros, o bien principios atingente a su actividad como el principio de solidaridad.

Por otra parte, en función del principio democrático y de subordinación de los institutos tradicionales al poder civil, la nueva Constitución elimina los capítulos referidos a las Fuerzas Armadas, de Orden y Seguridad Pública y el Consejo de Seguridad Nacional para quedar incluidos estos institutos en la Administración militar y/o policial según sea el caso, a fin de reafirmar su dependencia política, técnica y estratégica del Gobierno, y de los ministerios sectoriales.

Asimismo, el Banco Central, el Consejo para la Transparencia y las instituciones fiscalizadoras de la Administración Económica deben ser incorporadas a la Administración institucional, lugar en el Estado en que la ley les reconoce su autonomía, configura sus competencias, define un estatuto funcionarial especial con una carrera adecuada al rol institucional y establecerá el régimen de controles y responsabilidades ( $\sin$ perjuicio de la responsabilidad constitucional de sus órganos superiores), así como sus relaciones inter-institucionales deberá ser establecido en la ley.

Finalmente, con la finalidad de perfeccionar el sistema nacional de control y la Contraloría General de la República se ha llegado a plantear que puede transformarse éste en un organismo colegiado, de excelencia, nombrado por los poderes públicos democráticos, y responsable constitucionalmente, a cargo de la auditoría externa de la Administración y, por ende, de control de legalidad financiera y contable, de la inversión y gasto de recursos públicos; suprimiendo el control preventivo de legalidad, que pasaría ser sustituido por el control judicial residenciado en los tribunales administrativos que deberían crear. Esta es una idea digna de ser estudiada y correlacionarla con la importancia que tiene el organismo contralor hoy en nuestro Estado de Derecho.

En este mismo orden de ideas, se ha planteado la creación de un Tribunal de Cuentas, un tribunal superior, independiente y especial, que tendrá competencia en el juzgamiento de cuentas, velando por la sujeción o legalidad en el gasto público e inversión de recursos del Estado, todo a requerimiento de la Contraloría General de la República, del Estado Fisco o de las entidades legitimadas según lo establezca la ley. El Tribunal de Cuentas sería nombrado por los poderes públicos democráticos 
velando por una integración de excelencia profesional, y sus miembros serán responsables constitucionalmente.

Asimismo, como decíamos, la nueva Constitución prevé crear la Defensoría del Ciudadano, encargada de recibir las quejas de las personas y de los administrados en relación a la mala administración o deficiente funcionamiento de los servicios públicos de la Administración del Estado o de servicios públicos concesionados o gestionados por empresas privadas, y que importen la lesión de derechos fundamentales y de derechos humanos. La Defensoría del Ciudadano podrá instar a la tutela judicial de amparo de los derechos humanos ante los tribunales de justicia, y en general a la tutela del Derecho de la Constitución. La Defensoría expedirá informes públicos y ante el Congreso Nacional, formulará exhortaciones a la autoridad, recomendaciones, informes, activación de responsabilidades administrativas y jurídicas, contribuyendo además a activar el control político y el control social de los gobernantes.

\section{Gobierno y Administración Territorial}

El fortalecimiento de la descentralización que la nueva Constitución propone se estructura en dos unidades territoriales básicas, a saber, regiones y comunas.

En las regiones, por una parte, el Intendente conservará el rol de autoridad política o gubernativa, desconcentrada del Presidente de la República y de su exclusiva confianza y, por otra parte, existirá un Gobierno Regional, persona jurídica de derecho público, que tiene por función la Administración superior de la región. El Gobierno Regional reunirá los siguientes órganos: un Presidente Regional, una Asamblea Regional y los servicios públicos regionales, estructurados a partir del Gobierno.

La Asamblea Regional será elegida directamente por la ciudadanía de la región. A dicha Asamblea Regional o a la ciudadanía de la región le correspondería elegir al Presidente de la región, quien se desempeñará como órgano ejecutivo del Gobierno Regional. La Asamblea Regional conservará sus roles de órgano normativo, resolutivo y fiscalizador del Presidente de la región y de los servicios públicos y será la máxima instancia de representación y participación política de la ciudadanía.

La administración municipal, autónoma y descentralizada, seguirá descansando en un principio democrático en la generación de sus autoridades máximas, que serán el Alcalde y el Concejo, y en sus funciones propenderá al desarrollo comunal, a la integración y participación de la ciudadanía vecinal.

Para hacerse cargo del crecimiento urbano y la atención de servicios públicos o en la planificación territorial se plantea fortalecer las Áreas Metropolitanas y un Alcalde Mayor por cada una de ellas que será elegido por la reunión de alcaldes de las comunas concernidas en cada área. 


\section{Participación ciudadana}

La nueva Constitución establecerá mecanismos de participación ciudadana y/o instancias de democracia semi-directa en distintos niveles de decisión pública. Se propone incorporar el referéndum abrogatorio que deroga legislación inconveniente o injusta, el referéndum simple para definición de asuntos de interés nacional, regional y comunal; la iniciativa popular de ley y la revocatoria del mandato.

\section{Sistema electoral y Justicia Electoral}

La nueva Constitución debe contener una definición del sistema de representación electoral, que sea democrático y proporcional. Por ello, no sólo debe suprimirse el sistema electoral binominal, sino que la Constitución debe establecer las bases de un sistema proporcional corregido de conformidad a la nueva organización territorial, que establezca umbrales de representación mínima para las elecciones políticas y administrativas, permitiendo participar en los procesos electorales a partidos, movimientos o asociaciones políticas e independientes en condiciones que impidan la discriminación arbitraria.

Se ha debatido en orden a perfeccionar la Justicia Electoral, dotándola de amplia competencia en contenciosos electorales de todo tipo, contenciosos electorales administrativos, y electorales de grupos intermedios de la sociedad, permanente como institución, altamente cualificada en su integración letrada y generada por los poderes públicos democráticos. Los miembros de la Justicia Electoral quedarían sometidos a responsabilidad constitucional por infracción de la Constitución y notable abandono de deberes. Esta también es una nueva idea digna de ser estudiada para fortalecer nuestra Justicia Electoral.

\section{Poder Judicial}

La nueva Constitución propone una nueva Corte Suprema, la que debe ser tribunal máximo de casación y tribunal máximo de amparo de derechos fundamentales valorándose la especialización en salas del máximo tribunal. Se ha debatido acerca del establecimiento de un Consejo Nacional de la Justicia, parte del Poder Judicial, encargado de la función de gobierno y administración del Poder Judicial.

Lo anterior fortalece no sólo la independencia y autonomía del Poder Judicial, sino también la transparencia en la toma de decisiones, en materia administrativa y disciplinaria, y una efectiva carrera judicial fundada en los merecimientos del personal adscrito a este poder del Estado. ${ }^{9}$

Finalmente, el debate constitucional se hace cargo de completar este diseño de fortalecimiento del Poder Judicial, su independencia y autonomía, con la creación de 
tribunales administrativos como orden especializado que garantiza la seguridad jurídica, el imperio de la ley, tanto al Estado como a los ciudadanos administrados.

La nueva Constitución someterá a la justicia militar a un régimen compatible con la administración de justicia de un Estado de Derecho respetando el principio de sujeción del poder militar al civil.

\section{Tribunal Constitucional}

La nueva Constitución debe hacerse cargo de que el Tribunal Constitucional es una institución contra mayoritaria, por lo que debe fortalecer su rol de Tribunal y sus competencias de resolución de controversias, sin que se transforme en una "tercera cámara" legislativa o en un supremo intérprete de la Constitución, por encima de las demás instituciones del Estado.

Para ello, se propone una nueva generación del Tribunal Constitucional desde los poderes públicos democráticos, sin injerencia de la Corte Suprema, en número impar, eliminando el voto dirimente de su Presidente. Al mismo tiempo los miembros del Tribunal Constitucional deben ser responsables constitucionalmente de infracción a la Constitución y notable abandono de deberes, a través de la acusación constitucional, al igual que todas las autoridades del Estado.

Con la finalidad de racionalizar el rol contra mayoritario del Tribunal, se hace imperioso suprimir las competencias de control preventivo de constitucionalidad de las normas, de manera de no distorsionar la voluntad soberana del Congreso Nacional. Se requiere de un equilibrio entre la voluntad del Congreso y el respeto por la Constitución. Por lo mismo, se plantea reforzar el control ex-post o represivo del Tribunal, incorporando la posibilidad que los propios ciudadanos, a través de la recolección de un número determinado de firmas, las minorías cualificadas de las cámaras o el Defensor del Ciudadano, puedan ejercer una acción directa para solicitar la inconstitucionalidad de una determinada norma o cuerpo de normas de jerarquía legal o infralegal.

\section{Conclusiones}

Para concluir resta subrayar dos ideas-fuerza torales a modo de corolario de estas "bases" de la nueva Constitución.

Primero, la nueva Constitución debe ser institucional, democrática y participativa en su procedimiento genético; sea que resulte ser fruto del poder constituyente derivado (vía reforma total de la vieja Constitución) o del poder constituyente originario (congreso constituyente, asamblea constituyente y referéndum constituyente). ${ }^{10}$

10 Vega GaRCía, PEDRO DE, La reforma constitucional y la problemática del poder constituyente, Editorial Tecnos, Madrid, 1999. 
En razón de esta caracterización: institucional, democrática y participativa del procedimiento genético es que se propone incorporar al poder constituyente derivado el referéndum constituyente como mecanismo doble: para resolver los conflictos de bloqueo entre los órganos que ejercen la potestad constituyente (Presidente de la República y Congreso Nacional y sus cámaras) en cualquier etapa del iter procedimental, y para obtener la ratificación del obrar (decisión antes de convertirse en ley promulgatoria de la reforma constitucional) constituyente de los poderes instituidos por la soberanía del pueblo. También se hace necesario incorporar al alumbramiento de la nueva Constitución en el camino de la reforma total de la vieja Carta, mecanismos eficientes de estudio, deliberación y acuerdo en el interior del Congreso Nacional como verbi gratia la comisión bicameral; y de participación y consulta de la ciudadanía y de los movimientos sociales a través de audiencias públicas; todos mecanismos de resorte reglamentario interno pero muy valiosos. Adicionalmente el ejercicio del poder constituyente debe zafar de quórums reforzados ordinarios ( $3 / 5$ de parlamentarios en ejercicio) y extraordinarios (2/3 de parlamentarios en ejercicio); que operan formalmente como una garantía normativa de la hiper-rigidez de la Carta, pero que en la realidad son una herramienta para el bloqueo decisional y los vetos de contenido en la reforma constitucional. Por ello resulta razonable restituir el quórum reforzado de la Constitución de 1925 de mayoría absoluta de parlamentarios en ejercicio.

De esta manera la nueva Constitución supera el déficit de legitimidad democrática de la vieja Constitución, pero además supera el déficit democrático del poder constituyente derivado de la vieja Constitución. Ello significa que no sólo la nueva Constitución debe tener un procedimiento de reforma institucional, democrático y participativo, sino que además idealmente también la Constitución vigente concernida en la reforma total; lo que puede lograrse modificando in fieri el actual Capítulo XV de la Constitución.

Segundo, la nueva Constitución, sea fruto del poder constituyente derivado o del poder constituyente originario, debe estar soportada sobre un gran acuerdo nacional acerca de sus "bases", acuerdo que debe reflejar en la mayor medida de lo posible el pluralismo político e ideológico de la sociedad. La idea de acuerdo o pacto nacional de tipo político-constitucional subyacente a la nueva Constitución le confiere un plus de legitimidad y estabilidad normativa real. Primordialmente, tal acuerdo nacional debe ser gestado en el Congreso Nacional, si se opta por la reforma total de la vieja Constitución. En caso contrario, tal acuerdo debe ser gestado al interior del congreso constituyente o de la asamblea constituyente. En ambos casos (poder constituyente derivado o poder constituyente originario), la sociedad civil y sus movimientos sociales deben participar y ser escuchados en la usina de la nueva Constitución y expresarse como cuerpo electoral o ciudadanía a través de un referéndum constituyente.

En la construcción de la real legitimidad democrática de una nueva Constitución, se hace necesario superar la lógica de la imposición o la fuerza desnuda, presente en la 
vieja Carta y también en cierta medida en otras constituciones históricas de nuestro país. La idea de pacto o acuerdo nacional de tipo político-constitucional (plural, deliberativo, transparente) está al servicio de esa legitimidad democrática tan necesaria para un efectivo "patriotismo constitucional".

El por-venir del momento constitucional que atraviesa nuestro país, momento débil o fuerte, y las posibilidades concretas de la operación constituyente de tener éxito en nuestro proceso político tendrán su palabra a través del tiempo. ${ }^{11}$

11 VANOSSI, Jorge REINALDO A., Estudios de Teoría Constitucional, UNAM Instituto de Investigaciones Jurídicas, México DF, 2002. 